\title{
We are what we eat, plus some per mill: Using stable isotopes to estimate diet composition in Gyps vultures over space and time.
}

\author{
Allan Baino ${ }^{1}$, Grant Hopcraft ${ }^{2}$, Corinne Kendall ${ }^{3}$, Jason Newton ${ }^{2}$, Abdelkader Behdenna ${ }^{4}$, \\ and Linus Munishi ${ }^{5}$ \\ ${ }^{1}$ University of Greenwich Faculty of Engineering and Science \\ ${ }^{2}$ University of Glasgow \\ ${ }^{3}$ North Carolina Zoo \\ ${ }^{4}$ Epigene Labs \\ ${ }^{5}$ Nelson Mandela African Institute of Science and Technology
}

November 1, 2021

\begin{abstract}
1. Dietary studies in birds of prey involve direct observation and examination of food remains at resting and nesting sites. Although these methods accurately identify diet in raptors, they are time-consuming, resource-intensive, and associated with biases from the feeding ecology of raptors like Gyps vultures. Our study set out to estimate diet composition in Gyps vultures informed by stable isotopes that provide a good representation of assimilated diet from local systems.

2. We hypothesized that differences in Gyps vulture diet composition is a function of sampling location, and that these vultures move between Serengeti National Park and Selous Game Reserve protected areas to forage. We also, theorised that grazing ungulates are the principal items in Gyps vulture diet.

3. Through combined linear and Bayesian modelling, diet-derived from ?13C in Gyps vultures consisted of grazing herbivores across sites, with those in Serengeti National Park consuming higher proportions of grazing herbivores ( $>87 \%)$. ?13C differences in vulture feather subsets did not indicate shifts in vulture diet and combined with blood ?13C, vultures fed largely on grazers for 159 days before they were sampled. Similarly, ?15N values indicated Gyps vultures fed largely on herbivores. ?34S ratios separated where vultures fed when the two sites were compared. ?34S variation in vultures across sites resulted from baseline differences in plant ?34S values, though it is not possible to match ?34S to specific locations.

4. Our findings highlight the relevance of repeated sampling that considers tissues with varying isotopic turnover and emerging Bayesian techniques for dietary studies using stable isotopes. Findings also suggested limited vulture movement between the two local systems. However, more sampling coupled with telemetry is required to fully comprehend this observation and its implications to Gyps vulture ecology and conservation.
\end{abstract}

\section{Hosted file}

Manuscript_AB_2021.docx available at https://authorea.com/users/441875/articles/542310-weare-what-we-eat-plus-some-per-mill-using-stable-isotopes-to-estimate-diet-compositionin-gyps-vultures-over-space-and-time 